\title{
O mercenário tagarela e a tradução: os palavrões nas legendagens dos dois filmes de Deadpool (2016; 2018)
}

\section{Translating the merc with a mouth: swearwords in Deadpool's two movies (2016; 2018) and their subtitles}

\author{
Gabriela Spinola Silva ${ }^{1}$
}

\author{
Recebido em: 25/10/2019 \\ Aprovado em: 06/11/2019 \\ Publicado em: 19/12/2019
}

\begin{abstract}
Resumo: $O$ presente trabalho apresenta uma análise dos palavrões encontrados no áudio original dos filmes estadunidenses Deadpool (2016, dir. Tim Miller) e Deadpool 2 (2018, dir. David Leitch) e em suas legendas oficiais em português, presentes nos blu-ray de ambos os filmes. Trata-se de uma pesquisa descritiva, que enfatiza a problemática do uso de palavrões e compara suas traduções (feitas por pessoas diferentes, com orientações distintas em relação a como tratar os palavrões e em momentos diferentes, porém visando o mesmo público), usando as estratégias de legendagem descritas por Gambier (2003) como base para a análise dos palavrões encontrados. Sabe-se que existem várias restrições e tecnicalidades envolvidas no processo de legendagem (KARAMITROGLOU, 1998) e a tradução de palavrões, termos que nem sempre são aceitos pela sociedade, é uma das questões mais delicadas existentes na tradução audiovisual. Assim, além da comparação entre originais e traduções, busca-se ainda contextualizar o papel da censura aos palavrões (tanto a literal, no período da ditadura militar no Brasil, quanto a moral, que ocorre ainda hoje, por motivos de pudor das distribuidoras e do público) (FRANCO, 1991) nos resultados das análises realizadas.
\end{abstract}

Palavras-chave: Tradução Audiovisual; Legendagem; Palavrões; Deadpool.

\begin{abstract}
This work presents an analysis of the swearwords found in Deadpool (2016, dir. Tim Miller) and in Deadpool 2's (2018, dir. David Leitch) original audio in English and their translations in their official subtitles in Portuguese, avaliable in their blu-ray discs. This is a descriptive research which emphasizes how the use of swearwords can be problematic and compares both subtitles in their context: crafted by different people in a two-year gap who were probably distinctly oriented as to how to deal with swearwords, while also targeting the same audience. Gambier's (2003) subtitling strategies are used to analyse how the swearwords were translated. It is widely known that there are multiple restrictions and technicalities regarding the subtitling process (KARAMITROGLOU, 1998), and the translation of swearwords (terms upon which society often frowns) is one of the most intricate issues in this process. Thus, besides making comparisons between the original swearwords and their translations, this work also contextualizes censorship (both the literal one during Brazil's military dictatorship (1964-1985) and the moral one that remains up to these days due to both the distributor's and the audience's pudency) (Franco, 1991) and how it has affected the results of the analyses made in this work.
\end{abstract}

Keywords: Audiovisual Translation; Subtitling; Swearwords; Deadpool.

1. Bacharel em Tradução. Mestranda em Estudos da Linguagem na Universidade Federal de Goiás. Áreas de interesse de pesquisa são Tradução Audiovisual, Tradução Intersemiótica, e Literatura Fantástica. ORCID: 0000-0002-0972-6129. E-mail: lostunplugged@gmail.com. Orientador: Dr. Alexander Meireles da Silva 


\section{INTRODUÇÃO}

\section{Um panorama histórico sobre a tradução audiovisual no brasil, e os palavrões na tradução audiovisual}

A tradução audiovisual (TAV), enquanto prática profissional, surgiu durante os primórdios da sétima arte, com o advento do cinema falado ao final da década de 1920. A partir deste momento, os intertítulos (letreiros que apareciam durante e entre cenas nos filmes mudos, explicando as ações dos personagens ou descrevendo falas que eram impossíveis de serem proferidas devido à ausência de som) não mais se faziam necessários: afinal, agora havia som. Tal avanço tecnológico não apenas alterou toda a estrutura narrativa do cinema, abrindo amplos horizontes para a sétima arte a partir de então; como também gerou um sério problema no que concernia a distribuição internacional de obras cinematográficas: agora que há som em toda a duração do filme, e não apenas letreiros explicativos, como tornar acessíveis filmes produzidos em outros idiomas? Como traduzi-los?

De acordo com Freire (2015), em seu artigo O início da legendagem de filmes no Brasil, ocorreram aos distribuidores as mais diversas alternativas a esse aparente empecilho dos filmes. Cogitaram - e, ocasionalmente, até tentaram - regravar os filmes com atores diferentes, falando o idioma do país para o qual o filme seria distribuído; ou até mesmo dublá-lo (guardadas as devidas restrições, devido ao aparato tecnológico disponível à época), mas ambos os processos eram demasiado onerosos e recebiam duras críticas ante as tentativas de executá-los. No Brasil tentou-se, ainda, realizar a distribuição de livretos contendo as falas dos filmes traduzidas, como se fazia em óperas. Entretanto, o número de diálogos nos filmes foi aumentando exponencialmente e este método provou-se impraticável também: o público não conseguia acompanhar o filme e consultar o livreto ao mesmo tempo, em especial considerando-se o escuro característico das salas de cinema.

Todas as tentativas de lidar com o advento dos filmes falados fracassaram miseravelmente - isto é, até o momento em que surgiu a ideia de resgatar o princípio básico dos intertítulos e escrever diretamente na película o que estava sendo dito pelos personagens em cena. 
SILVA, G.S.

Enquanto nas versões em língua estrangeira e nas dublagens havia a substituição de um idioma por outro, na terceira alternativa experimentada em 1930 mantinha-se o costumeiro oferecimento da informação verbal sob a forma de informação escrita. Entretanto, tratava-se de não mais substituir os diálogos pelo texto escrito e nem intercalar cartelas entre as imagens, mas sim sobrepor ambas. Ao invés de trocar uma informação (verbal, em inglês) por outra (escrita, em português) ou alterná-las (texto / imagem e som / texto / imagem e som), elas passaram a ser oferecidas simultaneamente. (FREIRE, 2015, p. 204 - grifos do autor referenciado).

De acordo com Gottlieb (2002, p. 216, apud Ivarsson, 2010, p. 3), o primeiro filme "legendado" a ser exibido na história do cinema foi O cantor de jazz (1927), longametragem estadunidense exibido em com legendas em francês na cidade de Paris em 26 de janeiro de 1929. Em 17 de agosto do mesmo ano, o filme $A$ última canção (1929) foi exibido em Copenhague, com legendas em dinamarquês (GOTTLIEB, 2002, apud IVARSSON, 2010). Porém, segundo Freire (2015), o primeiro registro de exibição de um filme legendado em território nacional é de 29 de junho de 1929 - situando-se, portanto, entre as duas datas apresentadas por Gottlieb (2002) e, desta forma, colocando o Brasil em uma posição de pioneirismo no nascimento da tradução audiovisual. Apesar disso, a legendagem ainda era limitada e apresentava diversos problemas - à época, a confecção de legendas era extremamente trabalhosa e, portanto, elas serviam apenas para traduzir pontos que os tradutores considerassem mais importantes para a compreensão da trama. O primeiro filme a ser exibido no Brasil com legendas em toda a sua duração, em contraponto às legendas reduzidas anteriormente descritas, foi Alvorada de amor (1929), exibido desta forma pela primeira vez no dia 21 de abril de 1930 na cidade do Rio de Janeiro.

Ainda que tenha surgido nas primeiras décadas do século $X X$, a TAV pouco foi vista como objeto de estudos e pesquisas acadêmicas antes do ano de 1987, quando ocorreu a Conferência de Dublagem e Legendagem, organizada pela União Europeia de Radiodifusão na cidade de Estocolmo. Tal conferência trouxe enorme visibilidade para pesquisas sobre a área, que outrora dependiam de textos praticamente inacessíveis, encontrados apenas em bibliotecas de universidades europeias, para serem realizadas. Conforme diz Jorge Díaz Cintas (2009), no primeiro capítulo do livro New Trends in Audiovisual Translation, denominado Introduction - Audiovisual Translation: An Overview of its Potential, os trabalhos científicos na área da TAV muitas vezes dependiam de textos escassos publicados em revistas da área de cinema, e volta e meia pesquisadores europeus trocavam entre si artigos e manuscritos que nunca sequer haviam sido publicados. Dessa forma, era frequente que um indivíduo empreendesse uma pesquisa 
SILVA, G.S.

sobre tradução audiovisual sem saber que uma pesquisa similar estava sendo feita simultaneamente à sua. Contudo, após a supracitada conferência, houve um grande aumento na quantidade de trabalhos publicados a respeito da tradução audiovisual nos anos 90; inclusive com diversos autores definindo, cada um, cerca de dez modalidades de tradução audiovisual (como, por exemplo, legendagem, dublagem, audiodescrição, voiceover, etc.).

Este trabalho pretende debruçar-se sobre a legendagem - modalidade esta de tradução audiovisual que, segundo Díaz Cintas (2009), é a:

apresentação de um texto escrito, que geralmente situa-se na parte inferior da tela e consiste em uma paráfrase do diálogo original ocorrendo entre os falantes presentes na mídia apresentada; e, também, pode servir para traduzir outros elementos linguísticos que façam parte das imagens (placas, palavras, grafites, banners, entre outros) ou dos sons (como canções e narrações) presentes no material audiovisual a ser legendado. (DÍAZZ CINTAS, 2009, p. 5 - tradução minha) ${ }^{1}$.

Considerando os resultados da legendagem oficial do filme Deadpool (2016) encontrados na monografia $O$ palavrão em Deadpool: uma análise comparativa entre legendas oficiais e legendas de fãs, de Silva (2017), o presente artigo intenciona comparar as estratégias utilizadas na tradução dos palavrões na legendagem oficial dos dois longas-metragens do personagem Deadpool, um anti-herói oriundo dos quadrinhos da editora estadunidense Marvel.

Criado por Fabian Nicieza e Rob Liefeld em 1991, Deadpool (uma paródia de Deathstroke, vilão dos Jovens Titãs, grupo de heróis pertencente à editora rival, a DC Comics) inicialmente deveria ser um supervilão relacionado à equipe dos X-Men. Com o tempo, suas histórias foram cedendo mais ao espírito da paródia sob o qual foi concebido e o personagem agregou uma legião fiel de fãs. Sua primeira aparição no cinema foi no longa-metragem $X$-men Origens: Wolverine (2009); contudo, o filme sofreu duras críticas e a presença do personagem no longa frequentemente era descrita como "apagada", sem demonstrar a personalidade satírica e metalinguística que o tornou tão famoso, tudo isso a despeito do carisma inegável de seu intérprete, Ryan Reynolds (CINEMA EM CENA, 2009).

O primeiro filme solo do personagem, Deadpool (2016), foi um sucesso de crítica e público: com 84\% de aprovação da crítica no site Rotten Tomatoes (um agregador de

\footnotetext{
1Tradução de: [Subtitling involves] presenting a written text, usually along the bottom of the screen, which gives an account of the original dialogue exchanges of the speakers as well as other linguistic elements which form part of the visual image (inserts, letters, graffiti, banners and the like) or of the soundtrack (songs, voices off).
} 
SILVA, G.S.

notas de críticos de cinema), o filme conquistou a bilheteria mundial de 783 milhões de dólares, chegando a arrecadar treze vezes o seu orçamento quase irrisório de 53 milhões de dólares; e se tornando inclusive a maior bilheteria mundial de um filme com censura máxima nos EUA - recorde este quebrado por Deadpool 2 (2018) e, mais recentemente, Coringa (2019) (OMELETE, 2019). O segundo longa contou com um orçamento de 110 milhões de dólares (mais que o dobro do orçamento do longa anterior), alcançando um desempenho similar tanto nas bilheterias (onde fez 785 milhões de dólares) quanto nas críticas (alcançando um percentual de aprovação de 83\% no Rotten Tomatoes).

Houve, ainda, um "terceiro" filme: Era uma vez um Deadpool (2018) foi lançado como uma versão amigável e familiar do segundo longa-metragem, com um Deadpool sem palavrões e violência (excessivos, claro) raptando o ator Fred Savage e contando-Ihe a sua história, em referência ao filme $A$ princesa prometida (1987), no qual Savage interpretava um garoto que, acamado, ouvia o avô contar-lhe a saga de um fazendeiro que virou pirata e precisa superar vários obstáculos para reunir-se com sua princesa prometida (encontrando, de certa forma, um paralelismo com a história de Deadpool, seja em seu primeiro ou segundo filme; nos quais, apesar das diferentes circunstâncias, o protagonista sempre busca apenas reencontrar-se com sua amada Vanessa). Tal versão não foi tão bem recebida quanto os filmes anteriores (contando, apenas, com US $\$ 368$ milhões de bilheteria e 53\% de aprovação da crítica); contudo, foi feita visando cooperar com uma causa nobre: a cada ingresso do filme adquirido, um dólar seria doado para a associação Fuck Cancer, com o evidente objetivo de arrecadar fundos para o combate ao câncer. Tal associação, à época da exibição do filme nos cinemas, foi temporariamente renomeada como Fudge Cancer, a fim de ornar com o relançamento em versão censura livre do segundo filme do Mercenário Tagarela (DEADLINE, 2018).

A alcunha de "Mercenário Tagarela" (em inglês, Merc With a Mouth) foi concedida a Deadpool devido à sua natureza verborrágica, dinâmica e profana - está constantemente falando, fazendo alguma piada ou referência, quebrando a Quarta Parede (quando o personagem conversa diretamente com o público, ou quando ele se mostra consciente de que é um personagem dentro de alguma mídia - ou, no caso de Deadpool, ambos), ou xingando e declarando profanidades. Tais características, presentes em abundância nos quadrinhos, foram transferidas com maestria para as telonas, resultando não apenas em dois longas-metragens bem-sucedidos, como também na problemática tradutória apresentada e investigada no presente trabalho. 
SILVA, G.S.

Neste artigo, foram analisadas as legendas do blu-ray de Deadpool 2 (2018), e os resultados obtidos foram contrastados com aqueles encontrados no trabalho de Silva (2017), enfatizando a problemática do uso de palavrões - ainda um tabu na sociedade contemporânea e, geralmente, um problema dentro das traduções audiovisuais - bem como as traduções deles que, apesar de quaisquer divergências (o espaço de dois anos entre ambos os filmes, a classificação etária e a "liberdade" que tais classificações dariam aos tradutores para trabalharem com termos tabuízados na legenda - o primeiro filme teve a classificação indicativa de 16 anos, o segundo filme seria originalmente 18 anos no Brasil; contudo, teve sua classificação indicativa alterada para 16 anos devido à pressão popular na internet), visam agradar o mesmo público: desde os fãs mais assíduos de quadrinhos, que já estão familiarizados com o personagem-título, interpretado por Ryan Reynolds; até o grande público, que porventura assista qualquer um dos dois filmes sem ter a menor ideia do contexto da obra ou de qualquer informação acerca dela.

Segundo o dicionário Michaelis (2019), palavrão é "palavra grosseira, indecorosa, obscena; bocagem, obscenidade, pachouchada, palavrada, turpilóquio". Tal definição, ainda que vaga, deixa bastante evidente a conotação negativa que o termo carrega.

Sobre os palavrões, Esqueda (2012), em seu artigo O filme Tropa de Elite em espanhol: a questão da tradução dos palavrões, diz que:

Os palavrões são, portanto, variações socioculturais do léxico de uma língua, diretamente ligadas aos seus elementos afetivos e expressivos, sendo difícil definir seus limites, pois este problema está relacionado aos aspectos histórico-sociais de determinado povo e época, aos seus valores morais, à variação dos costumes, a tal ponto que o que era considerado um "termo proibido" ontem, hoje pode ser adotado por um grupo social, fazendo parte do vocabulário usual e familiar, ou seja, pode deixar de ser proibido devido ao uso frequente de determinado grupo (ESQUEDA, 2012, p. 146-147).

A despeito dessa dificuldade de delimitação citada por Esqueda (2012), Steven Pinker, em seu livro The Stuff of Thought (2007), dividiu os palavrões da língua inglesa em cinco categorias: sexo, fluídos corporais/órgãos, doenças/morte, religião/sobrenatural, e pessoas/grupos minoritários.

Neste trabalho, para fins de orientação para a seleção das falas e das legendas a serem analisadas, foi utilizado um quadro resumitivo agrupando as categorias de palavrões estabelecidas e descritas por Pinker, junto aos palavrões exemplificados por ele ao longo do capítulo The Seven Words You Can't Say On Television, elaborado por Silva (2017). 
Quadro 1 - Tipos de palavrões descritos por Pinker (2007)

\begin{tabular}{|l|l|}
\hline \multicolumn{1}{|c|}{ Tipos de palavrões } & \multicolumn{1}{c|}{ Palavrões (em inglês) } \\
\hline Sexo & $\begin{array}{l}\text { Fuck, screw, come, bastard, wanker, } \\
\text { cocksucker, motherfucker. }\end{array}$ \\
\hline Fluídos corporais e órgãos & $\begin{array}{l}\text { Shit, piss, fart, turd, cunt, pussy, tits, } \\
\text { prick, cock, dick, asshole, twat, ass. }\end{array}$ \\
\hline Doenças e morte & Não são mais usados. \\
\hline Religião e sobrenatural & Hell, damn, Jesus Christ. \\
\hline Pessoas e grupos minoritários & $\begin{array}{l}\text { Faggot, queer, dyke, spick, dago, kike, } \\
\text { wog, mick, gook, kaffir, nigger, bitch. }\end{array}$ \\
\hline
\end{tabular}

Fonte: SILVA (2017).

Devido à sua já mencionada natureza pejorativa, os palavrões tornam-se frequentemente objeto de censura. Durante a ditadura militar brasileira (1964-1985), a Lei no 5536 de 21 de novembro de 1968 (menos de um mês antes do Al-5, o qual efetivamente instalaria a censura em todos os âmbitos da vivência humana em território nacional) deu à Divisão de Censura de Diversões Públicas (uma repartição subordinada à Polícia Federal) o poder de avaliar as mais diversas obras culturais, como peças teatrais e obras cinematográficas; e vetá-las, caso elas atentassem "à segurança nacional e ao regime representativo e democrático (sic), à ordem e ao decôro (sic) públicos, aos bons costumes, ou ofensivas às coletividades ou as religiões ou, ainda, capazes de incentivar preconceitos de raça ou lutas de classes".

A despeito da lei que a regia aparentasse, por seu texto vago e questionavelmente redigido, ter a intenção de desestimular a criação de obras preconceituosas, a Divisão de Censura de Diversões Públicas (DCDP) era conhecida por vetar particularmente produções que contivessem nudez, homossexualidade, palavrões e qualquer tipo de inclinação ideológica que desviasse do que era estabelecido pelo regime militar como sendo o correto.

Uma das anedotas mais famosas sobre censura em obras estrangeiras à ocasião de sua chegada ao Brasil ocorreu com o filme Laranja mecânica (1971), lançado por aqui apenas em 1978. Após ter sua distribuição em território nacional constantemente negada pela DCDP, foi liberado somente sete anos após sua estreia em território inglês e estadunidense, porém com uma ressalva: em cenas que contivessem nudez, deveria haver uma bolinha preta cobrindo as partes pudendas dos personagens. Em determinado 
SILVA, G.S.

momento do longa, em uma cena em que uma personagem foge de um estupro e corre por todo o set, percorrendo toda a tela do cinema, a sincronia da tal bolinha preta com o corpo da personagem não era tão precisa quanto deveria ser e, assim, o que deveria ser uma cena tensa tornou-se, para o público brasileiro, algo um tanto quanto risível: uma bolinha preta perseguindo uma mulher desesperada e nua (MENEZES, 1997, p. 61).

A demora para se exibir o longa-metragem no Brasil foi tamanha que, à época do lançamento do filme em meio à nossa ditadura militar, a história de Alex DeLarge e seus drugues já havia sido retirada de circulação no próprio Reino Unido, a pedido do próprio diretor Stanley Kubrick, devido a ameaças de morte sofridas por sua família. O filme só foi reexibido no Reino Unido após a morte de Kubrick, no ano de 1999 (THE GUARDIAN, 2000).

Franco (1991), em sua dissertação de mestrado denominada Everything You Wanted To Know About Film Translation (But Did Not Have The Chance To Ask), discorre a respeito da censura em filmes não mais dentro do contexto da ditadura, tendo ela se encerrado seis anos antes da finalização do referido trabalho; mas sim, vinda das próprias produtoras, distribuidoras e estúdios de legendagem e dublagem responsáveis pelos filmes.

Os tradutores que trabalham com a mídia em vídeo explicam que a censura que existe atualmente neste meio é imposta pelos distribuidores, e que ela geralmente relaciona-se com questões morais tais como adultério e homossexualidade, entre outras. Segundo as respostas recebidas, cada distribuidor dita suas próprias regras, às quais devem ser seguidas à risca pelos tradutores. O crítico de cinema Rubens Ewald Filho (30/10/90), por exemplo, disse que o tradutor do estúdio Video Arte não tem permissão para usar palavras de baixo calão tais como "merda", a menos que seja estritamente necessário. V.M., do Duplilab, diz que por vezes o distribuidor (no caso, a Warner) altera o texto já traduzido.

Para o tradutor S.R.S., a censura existe principalmente quando questões sociais (como, por exemplo, "drogas") entram em questão. Quanto ao uso de palavrões, ele elaborou, há muito tempo, uma forma diferente e bemhumorada de se lidar com eles na hora de traduzir: é através dos trocadilhos que ele se faz entender, vide o uso de "vá à mesbla" ou "fofase" (em Schild, Jornal do Brasil, 08/11/1984) (FRANCO, 1991, p. 56 tradução minha) ${ }^{2}$.

\footnotetext{
2 Tradução de: The translators who work for the video medium explain that the censorship which now exists in the film rendering activity is imposed by the distributors, and that it relates mainly to moral matters, such as adultery, homosexuality, etc. According to their answers, it seems that each distributor dictates rules that have to be followed by the translators. Reviewer Rubens E. Filho (30/10/90), for example, said that the translator of Video Arte is not allowed to use certain rude words such as "merda", unless it is strictly necessary. VM, from Duplilab, said that sometimes the distributor (Warner) can alter the already translated text. For translator SRS, censorship, which is also imposed by distributors in the cinema medium, is a problem mainly whenever social matters (e.g. "drugs") are concerned. As regards the use of rude words, he
} 
Diante de tais declarações, Franco (1991) diz que "se, por um lado, as distribuidoras não querem chocar o público; por outro lado, estão ridicularizando o trabalho dos tradutores" (FRANCO, 1991, p.57 - tradução minha). ${ }^{3}$

Considerando-se as descobertas feitas por Franco (1991) em seu mestrado e o fato de trabalhos como o presente artigo ainda existirem e serem necessários, quase 35 anos após o fim da ditadura militar, é possível inferir que o moralismo vigente da época enraizou-se no meio da tradução audiovisual (contudo, tal moralismo não se limita a esse meio, tampouco ao espaço temporal do trabalho de Franco, 1991, como o episódio da censura a um quadrinho da Marvel na Bienal do Livro no Rio de Janeiro em setembro de 2019 bem nos mostrou) e, apesar dos avanços e da constante quebra de paradigmas propiciados pelo advento da internet e sua consequente democratização do acesso à informação, ainda é notável a vigência da neutralização e até mesmo a eliminação de palavrões dos mais diversos meios de entretenimento e comunicação. Este moralismo, em muito interfere - e sempre interferiu - na produção da tradução para legendagem e dublagem pois, além da necessidade de se atender às exigências do cliente, ou seja, o distribuidor, o tradutor precisa, ainda, atentar-se ao público.

Para a maioria dos tradutores (cinco de oito e, dentre estes cinco, o diretor de dublagem G.B.), a censura atual ainda funciona como uma forma de restrição do processo de tradução para dublagem televisiva. Contudo, esta censura é majoritariamente imposta pelo público e novamente tangencia questões de moralidade. Como diz o tradutor E.B.: "aí vem a Liga das Senhoras Católicas reclamar como um palavrão passa na TV naquele horário".

Como consequência disso, a maioria dos tradutores para dublagem televisiva vê-se obrigado a substituir termos ofensivos e demais verbetes "pesados"; contudo, dependendo do conteúdo do filme, tais substituições acabam por resultar em cacoetes inteligíveis. Por exemplo, em um filme sobre drogas, V. de Sá (Folha de São Paulo, 13/08/88, p. 1) aponta que "um viciado em cocaína faz qualquer coisa para obter 'farinha', gangs (sic) de adolescentes usam seringas para injetar 'remédio' (...)".

Desta forma, a censura, que funciona como uma camisa-de-força nos processos de legendagem e dublagem é imposta seja internamente (pelo distribuidor, no home video e no cinema) ou externamente (pelo público, na televisão). As consequências disso se refletem na qualidade dos produtos finais: a tradução para dublagem e legendagem do home video, do cinema e da televisão. (FRANCO, 1991, p. 57-58 - tradução minha) ${ }^{4}$

\footnotetext{
invented, a long time ago, a different and good-humoured way of translating them: through making puns, such as "vá à mesbla" or "fofa-se" (in Schild, Jornal do Brasil, 08/11/1984).

3 Tradução de: This means that if, on the one hand, distributors do not want to shock the audience, they are, on the other hand, ridiculing the translators' work.

${ }^{4}$ Tradução de: As most of the dubbing translators agree (five out of eight), including the dubbing director GB, current censorship still acts as a severe constraint in the dubbing translation process for the television
} 
É preciso considerar o fato de que o trabalho de Franco (1991) foi escrito a quase três décadas atrás, em um mundo não tão globalizado e certamente não tão conectado com a internet como o mundo em que vivemos hoje. As expectativas, portanto, eram distintas das que temos contemporaneamente, e o acesso à informação também. Atualmente, quase na segunda década do século XXI, as coisas são diferentes - porém, se realmente ainda não existisse nenhuma forma de censura na tradução audiovisual, a presente pesquisa, assim como diversas outras aqui citadas, não teria razão de ser. A despeito de tudo isto, é possível dizer que esta autocensura moralizante vem sendo alterada com o tempo. Por exemplo, Fotios Karamitroglou, em seu texto A Proposed Set of Subtitling Standards in Europe (1998), tenta descrever o que era feito na Europa em termos de legendagem no final dos anos 90 . Ele, também, propõe parâmetros para a legendagem que fossem o mais próximo do ideal possível, levando em consideração a capacidade e velocidade de leitura do público europeu à época. Dentre os vários parâmetros por ele estabelecidos, ele define que os palavrões "não devem ser censurados, a menos que seja necessário devido ao limite de caracteres" (KARAMITROGLOU, 1997, p. 14). ${ }^{5}$

Gomes (2014), em sua monografia $A$ tradução para o português dos palavrões do filme Os Infiltrados, de Martin Scorsese, valendo-se também das estratégias de Yves Gambier (2003) a serem descritas no próximo tópico do presente artigo, encontra uma predominância da omissão na tradução das legendas, a qual constitui $63 \%$ das ocorrências encontradas por ele no filme Os Infiltrados (2006). O filme, contudo, foi lançado em 2006 - exatamente uma década antes do primeiro longa-metragem do Mercenário Tagarela chegar às telonas. Dadas as mudanças tecnológicas e comportamentais ocorridas na sociedade durante esses dez anos, é possível que, em uma década, muitos outros aspectos também tenham sofrido alterações - inclusive o

medium, but it is mainly imposed by the audience, as translator EB remarks "aí vem a Liga das Senhoras Católicas reclamar como um palavrão passa na TV naquele horário", and it acts mainly in questions related to morality. As a result, most TV dubbing translators have to replace rude words with milder terms as well as minimize other "heavy" vocabulary, which, depending on the film, may result in unintelligible utterances. Such is the case of a film about drugs in which, as V. de Sá. (Folha de S. Paulo, 13/08/88:1) illustrates, "um viciado em cocaína faz qualquer coisa para obter 'farinha'; gangs de adolescentes usam seringas para injetar 'remédio' (...). As observed, censorship that functions as a constraint in the subtitling and dubbing translation processes is imposed externally either by the distributor (in the video and cinema media) or by the audience (in the television medium). The consequence of this is reflected, although to a small extent, on the quality of video subtitling translation products and, to a great extent, on the quality of cinema subtitling and television dubbing translation products.

5 Tradução de: Taboo words should not be censored unless their frequent repetition dictates their reduction for reasons of text economy. 
SILVA, G.S.

posicionamento geral de estúdios, de tradutores e, talvez, até do próprio público sobre a necessidade de se ocultar palavrões das legendas de filmes.

Por sua vez, a Netflix, uma plataforma de streaming mundialmente popular e que pode ser acessada em televisões, smartphones, computadores e tablets (ou seja, necessita adequar suas legendas para serem lidas em todos os tipos de telas, e por todos os tipos de público), também discorre a respeito da tradução de palavrões, porém o faz de uma forma vaga: "os diálogos não devem jamais ser censurados. Palavrões devem ser registrados o mais fielmente possível" 6 . Tema já debatido à exaustão ao longo de cerca de 60 anos de Estudos da Tradução, o conceito de "fidelidade" é algo considerado extremamente subjetivo. Contudo, é notável o esforço por parte da plataforma em tentar preservar a presença desses termos tabuízados nas legendas, o que contrasta seriamente com o esforço visto no trabalho de Franco (1991), há quase 30 anos, por parte de distribuidoras e estúdios a fim de reduzir ao máximo a quantidade de palavrões entregues em suas traduções audiovisuais.

\section{METODOLOGIA DA ANÁLISE COMPARATIVA: PALAVRÕES E PROCEDIMENTOS}

Antes mesmo da coleta dos palavrões, ocorreu a decisão de se utilizar, na presente pesquisa, as estratégias de tradução audiovisual estabelecidas por Yves Gambier (2003). Gambier (2003) denominou cinco principais estratégias que resumem as ações tomadas durante a legendagem de algum produto audiovisual. Essas estratégias foram aplicadas por Esqueda (2012) em seu trabalho, que também intencionava observar as traduções de palavrões em uma obra audiovisual. A autora descreve essas estratégias principais, que são:

Quadro 2 - Estratégias de Gambier (2003)

\begin{tabular}{|l|l|}
\hline \multicolumn{1}{|c|}{ Estratégia } & \multicolumn{1}{|c|}{ Descrição } \\
\hline Redução & $\begin{array}{l}\text { Reduz-se o número de palavras ou o } \\
\text { conteúdo expresso }\end{array}$ \\
\hline Omissão & Ocorrem cortes drásticos \\
\hline Neutralização & $\begin{array}{l}\text { Há uma adequação ao conteúdo com uso } \\
\text { de expressões anômalas }\end{array}$ \\
\hline Expansão & Comunicação de referências culturais \\
\hline Equivalência ou imitação & Uso de expressões idênticas \\
\hline
\end{tabular}

Fonte: SILVA (2017, com base em ESQUEDA, 2012).

${ }^{6}$ Tradução de: Dialogue must never be censored. Expletives should be rendered as faithfully as possible. 
Para o presente trabalho, foi selecionado um roteiro não-oficial do filme Deadpool 2 (2018), que contivesse todas as falas do mesmo. Esse roteiro foi escolhido em detrimento do script oficial por apresentar todas as falas do filme na íntegra. Algumas falas foram alteradas no corte final do longa-metragem, ou feitas de improviso; então, ao assistir ao filme, ouvir o áudio e ler o roteiro oficial, é perceptível o fato de que algumas falas simplesmente não coincidem. A utilização de material oficial não seria, portanto, adequada para a realização da análise proposta neste trabalho.

A fim de coletar os fragmentos textuais que contivessem os palavrões presentes nas categorias de Pinker (2007), o roteiro não-oficial foi copiado e colado em um arquivo de formato.doc. Na sequência, foi utilizada a ferramenta de edição do Word "Localizar", que permite que se encontre, inclusive, as variações dos palavrões. Ao pesquisar por fuck, a ferramenta "Localizar" também nos apresenta demais termos que contenham fuck dentro do vocábulo: por exemplo, os termos fucking, fuck up e fuckface aparecem.

Assim, elaborou-se um quadro (o qual, por questões de limitação espacial, não será reproduzido integralmente nesse artigo) que detalha as ocorrências dos palavrões dentro do filme. O quadro é composto por três colunas: na primeira, denominada "Expressão original", é apresentada a fala original, em inglês, contendo o palavrão, com grifos amarelos. A segunda coluna mostra a legenda equivalente presente no blu-ray, com grifos verdes nos palavrões, caso tenham sido traduzidos. Já a terceira coluna apresenta a estratégia utilizada na legendagem oficial, dentre aquelas descritas por Gambier (2003).

Quadro 3 - Excerto do quadro com os palavrões do filme Deadpool 2 (2018), suas traduções e suas estratégias

\begin{tabular}{|l|l|l|}
\hline \multicolumn{1}{|c|}{ Expressão original } & \multicolumn{1}{c|}{ Tradução oficial } & \multicolumn{1}{c|}{ Estratégia utilizada } \\
\hline Fuck Wolverine. & Foda-se o Wolverine. & Imitação \\
\hline $\begin{array}{l}\text { Then, the hairy } \\
\text { motherfucker ups the } \\
\text { ante by dying! }\end{array}$ & $\begin{array}{l}\text { Aí o puto cabeludo } \\
\text { aumenta a aposta e } \\
\text { morre. }\end{array}$ & Neutralização \\
\hline
\end{tabular}

Fonte: a autora

A primeira coluna a ser preenchida foi a coluna "Expressão original", através do já descrito método de pesquisa no Word dentro do arquivo com o roteiro não-oficial colado. A coluna "Tradução oficial", referente às legendas do blu-ray e com grifos verdes, foi preenchida ao reassistir ao filme em blu-ray, na televisão - ao identificar, no áudio em inglês algum dos palavrões anteriormente selecionados por meio do roteiro não-oficial, pausava-se o filme para digitar a legenda, presente na tela, em seu respectivo espaço no 
SILVA, G.S.

quadro. Foram ignoradas legendas que possuíssem palavrões, mas cujo áudio original não apresentasse quaisquer termos tabuízados pois, como critério de seleção, decidiu-se partir do áudio e das falas originais em inglês e dos palavrões ali presentes.

A coluna referente às estratégias de tradução utilizadas foi preenchida por meio da observação e análise das falas contidas em suas respectivas colunas anteriores, tendo como base as estratégias abordadas no quadro 2 .

Em seguida, a coluna referente às estratégias foi copiada e colada em um arquivo .txt, o qual foi inserido no programa AntConc (um software comumente utilizado para a análise de corpus), em que, na aba WordList, foi apresentada a frequência de cada palavra (no caso, cada palavra é correspondente a uma das estratégias de Gambier, 2003, apresentadas no quadro 2), resultando nos números presentes no quadro 4 , o qual evidencia quais foram as estratégias mais utilizadas na legendagem oficial do filme Deadpool 2 (2018).

Quadro 4 - Estratégias utilizadas nas traduções dos palavrões do filme Deadpool 2 (2018).

\begin{tabular}{|c|c|}
\hline Estratégia & Ocorrências \\
\hline Imitação & 76 \\
\hline Omissão & 52 \\
\hline Neutralização & 20 \\
\hline Expansão & 12 \\
\hline Redução & 0 \\
\hline Total & 159 \\
\hline
\end{tabular}

Fonte: a autora.

Tais resultados contrastam consideravelmente com o que foi encontrado por Silva (2017) a respeito da tradução dos palavrões na legenda oficial de Deadpool (2016):

Quadro 5 - Estratégias utilizadas nas traduções dos palavrões do filme Deadpool (2016).

\begin{tabular}{|c|c|}
\hline Estratégia & Ocorrências \\
\hline Imitação & 53 \\
\hline Omissão & 52 \\
\hline Neutralização & 18 \\
\hline Redução & 2 \\
\hline Expansão & 2 \\
\hline Total & 127 \\
\hline
\end{tabular}

Fonte: SILVA (2017).

Revista do SELL, Uberaba - V. 8 n. 2, p. 314-332, Jul./Dez. - 2019. 
Contrariando a hipótese levantada no início de sua monografia, Silva (2017) descobriu que a estratégia predominante na legendagem dos palavrões presentes no filme Deadpool (2016) não era a omissão, e sim, a imitação. Contudo, houve quase um empate entre as duas estratégias, ou seja, pode-se inferir que, no primeiro filme, a orientação recebida por Mario Menezes, tradutor responsável pela legendagem do longametragem, possivelmente foi a de não se esquivar dos palavrões, mas também a de não exagerar no uso destes na legenda.

Já no segundo filme, com um resultado completamente diferente, onde a imitação realmente prevalece, com 25 ocorrências a mais do que a segunda estratégia mais frequente (omissão), é possível inferir que a orientação dada aos tradutores - agora não somente Mario Menezes como também seu sobrinho, Guilherme Menezes - foi quase diametralmente oposta: não se esquivem dos palavrões e sejam o mais criativos possível. De acordo com entrevista dos tradutores à seção de entretenimento do portal Bol, tal inferência de fato condiz com a realidade.

E não pense que os tradutores "aliviam" na linguagem, como costumava acontecer no passado. "Nós não mudamos muita coisa por achar pesado demais, principalmente se tratando de Deadpool. Como é um filme em que finalmente temos liberdade para zoar e escrever besteira, tentamos manter o nível, mas com cuidado. Não podemos nem 'ganhar' nem 'perder', fazendo uma coisa que seja ofensiva sem estar assim no inglês ou uma coisa que acabe ficando sem graça por suavizarmos", conta Guilherme. (BOL, 2018).

Considerando-se, então, os resultados obtidos e a declaração anteriormente citada, feita por um dos responsáveis pela legendagem do filme, pode-se presumir que a orientação dada aos tradutores responsáveis pela legendagem de filmes tem mudado progressivamente, seguindo uma visão mais progressista de mundo e relevando o caráter tabuízado dos palavrões. Contudo, observando a mesma fala de Guilherme Menezes, também é possível inferir que tais orientações ainda são a exceção, e não a regra: ele mesmo diz que Deadpool 2 (2018) "é um filme em que finalmente temos liberdade para zoar e escrever besteira", subliminarmente declarando que não tem a oportunidade de exercer livremente sua criatividade e manter os palavrões em todos os longas-metragens para os quais faz a legenda. 


\section{CONSIDERAÇÕES FINAIS}

Alguns objetivos principais marcaram este trabalho: a apresentação de um panorama amplo sobre a história da tradução audiovisual (mais especificamente a modalidade de TAV denominada legendagem) e da tradução dos palavrões nas TAVs no Brasil; assim como a análise dos palavrões encontrados no áudio original do filme estadunidense Deadpool 2 (2018) e suas traduções, de acordo com as estratégias de Gambier (2003). Ainda, almejou-se traçar uma comparação entre os resultados do presente trabalho e os encontrados na análise feita por Silva (2017) dos palavrões presentes no filme Deadpool (2016), tal como contribuir com as pesquisas no campo da tradução audiovisual. Além disso, foi levantada a hipótese de que os palavrões, na legenda oficial do blu-ray, seriam majoritariamente amenizados (ou, conforme a nomenclatura das estratégias de Gambier, 2003; omitidos, neutralizados ou reduzidos).

A respeito das estratégias listadas por Gambier (2003), este trabalho revelou que as estratégias de imitação e omissão foram as mais utilizadas, apresentando um resultado similar ao encontrado por Silva (2017); contudo, havendo aqui uma discrepância bem maior entre as ocorrências de imitação e omissão, em contraste ao quase empate entre as duas estratégias encontrados por Silva (2017). Além disso, a hipótese levantada de que os palavrões seriam majoritariamente eliminados nas legendas não se confirmou, visto que a estratégia mais utilizada foi a imitação. Contudo, a omissão mais uma vez é a segunda estratégia mais utilizada, o que indica um possível hábito já internalizado dos tradutores audiovisuais de eliminarem os turpilóquios encontrados em seus objetos de prática profissional.

Faz-se necessário pontuar, contudo, que este trabalho não foi feito com o intuito de criticar, avaliar ou julgar os responsáveis pelas traduções aqui vistas; mas sim, de buscar compreender e, possivelmente, justificar as decisões tomadas nas traduções de palavrões presentes em materiais audiovisuais.

Se, como dizia o cineasta e crítico francês Éric Rohmer, "todo bom filme é também um documento de sua época", então Deadpool (2016) e Deadpool 2 (2018) são registros do culto contemporâneo aos super-heróis (e aos anti-heróis, como é o caso do protagonista do objeto deste trabalho), às traduções intersemióticas que transformam quadrinhos e livros nos mais variados materiais audiovisuais, e à expectativa (vinda do público) de fidedignidade ao ver um personagem conhecido e cultuado sendo retratado 
SILVA, G.S.

em uma nova mídia. Desta forma, espera-se que aqueles que legendaram (e que, quem sabe, legendarão) estas obras audiovisuais e seus derivados tenham em mente todo esse contexto ao exercer tal atividade, levando os palavrões em conta como característica indissociável do personagem que os profere.

Este trabalho, portanto, contribui com estudos na área de Tradução Audiovisual, mais especificamente dentro do escopo da legendagem e da tradução de palavrões e termos tabuízados, evidenciando a necessidade de se provocar uma reflexão nos envolvidos na tradução audiovisual sobre a forma como os palavrões são vistos dentro desta área da Tradução e, portanto, tratados e traduzidos. O trabalho observou traduções distintas de diversos palavrões e buscou entendê-las enquanto pertencentes a um sistema frequentemente submisso a censuras (a tradução oficial, do blu-ray); seja a oficial, vinda dos estúdios e produtoras com medo de ofender e alienar seu público, seja a censura autocrítica dos tradutores das legendas enquanto membros de uma sociedade fortemente moralista.

Espera-se que este trabalho possa aprofundar e dar continuidade aos estudos sobre estas temáticas, incitando a elaboração de mais trabalhos como este, para que tradutores e demais profissionais da área de produção audiovisual possam se beneficiar dos conhecimentos e informações compartilhados.

\section{REFERÊNCIAS}

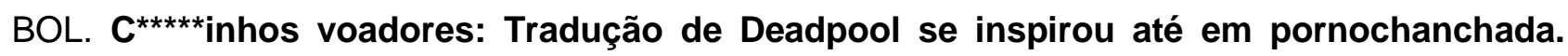
Disponível em: https://www.bol.uol.com.br/entretenimento/2018/05/17/cinhos-voadores-traducaode-deadpool-se-inspirou-ate-em-pornochanchada.htm. Acesso em: 05 set. 2019.

BOX OFFICE MOJO. Deadpool (2016). Disponível em: http://www.boxofficemojo.com/movies/?page=main\&id=deadpool2016.htm. Acesso em: 01 out. 2019.

BOX OFFICE MOJO. Deadpool 2 (2018). Disponível em: https://www.boxofficemojo.com/movies/?id=foxmarvel18.htm. Acesso em: 01 out. 2019.

BOX OFFICE MOJO. Once Upon a Deadpool (2018). Disponível em: https://www.boxofficemojo.com/movies/?id=deadpool3.htm. Acesso em: 01 out. 2019.

CINEMA EM CENA. X-Men Origens: Wolverine. Disponível em: https://cinemaemcena.com.br/critica/filme/6442/x-men-origens-wolverine. Acesso em 24 out. 2019. DEADLINE. 'Deadpool 2': Year's Top R-Rated Hit Gets New Life as PG-13 Film. Disponível em: https://deadline.com/2018/11/deadpool-ryan-reynolds-disney-pg13-marvel-1202495981/. Acesso em: 01 out. 2019. 
SILVA, G.S.

DEADPOOL. Direção: Tim Miller. Produção: Rhett Reese, Paul Wernick, Ryan Reynolds. Vancouver (CA): Twentieth Century Fox, Marvel Entertainment, TSG Entertainment, 2016, 1 Bluray.

DEADPOOL 2. Direção: David Leitch. Produção: Rhett Reese, Paul Wernick, Ryan Reynolds. Vancouver (CA): Twentieth Century Fox, Marvel Entertainment, TSG Entertainment, 2018, 1 Bluray.

DÍAZ CINTAS, Jorge. New trends in audiovisual translation. 1 ed. Bristol, Reino Unido: Multilingual Matters, 2009. 283 p.

ERA UMA VEZ UM DEADPOOL. Direção: David Leitch. Produção: Rhett Reese, Paul Wernick, Ryan Reynolds. Vancouver (CA): Twentieth Century Fox, Marvel Entertainment, TSG Entertainment, 2018, 1 Blu-ray.

ESQUEDA, Marileide Dias. O filme "Tropa de Elite" em espanhol: a questão da tradução dos palavrões. Abehache. v. 2, n. 3, São Paulo, p. 145-161, 2012.

FRANCO, Eliana Paes Cardoso. Everything you wanted to know about film translation (But Did Not Have The Chance To). Dissertação (Mestrado em Letras) - Universidade Federal de Santa Catarina. Florianópolis, SC, 1991.

FREIRE, Rafael De Luna. O início da legendagem de filmes no Brasil. Matrizes, São Paulo, v. 9, n. 1, p. 187-211, 2015. Disponível em: http://www.journals.usp.br/matrizes/article/view/100680. Acesso em: 25 set. 2019.

GAMBIER, Yves. Screen Transadaptation: Perception and Reception. The Translator: Studies in Intercultural communication. Manchester, v. 9, n. 2, p. 171-189, 2003. Special Issue. Screen Translation.

GOMES, Fernando Franqueiro. A tradução para o português dos palavrões do filme Os Infiltrados, de Martin Scorsese. 2014. 45 f. Monografia (Bacharelado em Tradução) Universidade Federal de Uberlândia.

GOTTLIEB, Henrik. Titles on Subtitling 1929-1999. An International Annotated Bibliography: Interlingual Subtitling for Cinema, TV, Video and DVD. Rassegna Italiana di Linguistica Applicata, Roma, v. 34, n. 1-2, p. 215-397, 2002.

IVARSSON, Jan. The History of Subtitles in Europe. In: FONG, Gilbert C.F.; AU, Kenneth K.L. (eds). Subtitling in a World Context. Hong Kong: The Chinese University, 2010. p. 3-12.

KARAMITROGLOU, Fotios. A Proposed Set of Subtitling Standards in Europe. Translation Journal, $\quad$ v. $\quad 2, \quad$ n. 2 , p. 1-15, abr. 1998. Disponível em: http://translationjournal.net/journal/04stndrd.htm. Acesso em: 25 set. 2019.

MICHAELIS ON-LINE. Palavrão. http://michaelis.uol.com.br/busca?r=\&f=\&t=\&palavra=palavr\%C3\%A3o. Acesso em: 25 set. 2019. MENEZES, Paulo. Laranja Mecânica violência ou violação?. Tempo social, v. 9, n. 2, p. 53-77, 1997. Disponível em: http://www.scielo.br/pdf/ts/v9n2/v09n2a04.pdf. Acesso em: 26 set. 2019.

Revista do SELL, Uberaba - V. 8 n. 2, p. 314-332, Jul./Dez. - 2019. 
SILVA, G.S.

NETFLIX PARTNER HELP CENTER. Brazilian portuguese timed text style guide. Disponível em: https://backlothelp.netflix.com/hc/en-us/articles/215600497-brazilian-portuguese-timed-textstyle-guide. Acesso em: 26 set. 2019.

OMELETE. Ryan Reynolds parabeniza Coringa por recorde de bilheteria. Disponível em: https://www.omelete.com.br/coringa-joker/coringa-filme/coringa-ryan-reynolds-parabens. Acesso em: 05 nov. 2019.

PRESIDÊNCIA DA REPÚBLICA. Lei no 5.536, de 21 de novembro de 1968. Disponível em: http://www.planalto.gov.br/ccivil_03/leis/1950-1969//5536.htm. Acesso em: 26 set. 2019.

ROTTEN TOMATOES. Deadpool (2016). Disponível em:

https://www.rottentomatoes.com/m/deadpool. Acesso em: 01 out. 2019.

ROTTEN TOMATOES. Deadpool 2 (2018). Disponível em:

https://www.rottentomatoes.com/m/deadpool_2. Acesso em: 01 out. 2019.

ROTTEN TOMATOES. Once Upon a Deadpool (2018). Disponível em: https://www.rottentomatoes.com/m/once_upon_a_deadpool. Acesso em: 01 out. 2019.

SILVA, Gabriela Spinola. O palavrão em Deadpool: uma análise comparativa entre legendas oficiais e legendas de fãs. 2017. 56 f. Monografia (Bacharelado em Tradução) - Universidade Federal de Uberlândia.

THE GUARDIAN. The old ultra-violence. Disponível em: https://www.theguardian.com/film/2000/mar/03/fiction. Acesso em: 24 out. 2019.

\section{Como citar este artigo (ABNT)}

SILVA, G.S. O mercenário tagarela e a tradução: os palavrões nas legendagens dos dois filmes de Deadpool (2016; 2018). SELL, Uberaba, MG, v. X, n. X, p. XXX-XXX, 2019. Disponível em: <inserir link de acesso>. Acesso em: inserir dia, mês e ano de acesso. DOI: inserir link do DOI.

\section{Como citar este artigo (APA)}

SILVA, G.S. (2019). O mercenário tagarela e a tradução: os palavrões nas legendagens dos dois filmes de Deadpool (2016; 2018). SELL, X (X), XXX-XXX. Recuperado em: inserir dia, mês e ano de acesso de inserir link de acesso. DOI: inserir link do DOI. 